\title{
Synergy of Herbal Oil Extracts/Antibiotic Combinations in Drug- Resistant Uropathogenic E. coli
}

\author{
D.M. Hassan ${ }^{1 *}$ (D) , S.M. Elnagdy², A.Abu-Taleb², B.A. Gomaa ${ }^{2}$ and \\ N.S. Soliman ${ }^{1}$ \\ ${ }^{1}$ Department of Clinical and Chemical Pathology, Faculty of Medicine, Cairo University, Cairo - 11562, Egypt. \\ ${ }^{2}$ Department of Botany and Microbiology, Faculty of Science, Cairo University, Cairo - 12613, Egypt.
}

\begin{abstract}
Urinary tract infection (UTI) is the second most common infection worldwide and Escherichia coli (E. coli) is the chief causing pathogen. Antimicrobial resistance results into therapeutic failure. This study aimed to incrimination of $E$. coli as uropathogen harbouring cnf1 gene (necrotoxin virulence)and to detect the in vitro antimicrobial efficacy of several selected essential oil/antibiotic combinations against the isolated uropathogenic $E$. coli. Well diffusion method was used to determine the minimal inhibitory concentrations (MICs) to essential oils (EOs) individually. Broth micro-dilution method was used to determine the minimal inhibitory concentrations (MICs) to antibiotics and in combinations, to figure out the interactive efficacy of tested combinations. Necrotoxin cnf1 gene was detected by PCR assay. E.coli was detected at a rate of $40.6 \%$ of the isolated urinary pathogens and $47.8 \%$ showed ESBL production. In-vitro synergistic efficacy was only observed for cinnamon oil/gentamycin combination in $100 \%$ of selected 15 tested isolates (P-value $<0.001$ ). The cnf1 virulence gene was detected in $40 \%$ of tested isolates showing no significant correlation the conferred pattern of resistance among the $E$. coli isolates. Cinnamon/gentamycin combination against drug-resistant $E$-coli is promising and can pave the way for further clinical trials to formulate pharmacological combinations.
\end{abstract}

Keywords: Antibiotics, essential oils, necrotoxin gene, synergistic effect

*Correspondence: dinamhassan12@gmail.com; +201006911788

(Received: March 04, 2020; accepted: April 16, 2020)

Citation: Hassan DM, Elnagdy SM, Abu-Taleb A, Gomaa BA, Soliman NS. Synergy of Herbal Oil Extracts/Antibiotic Combinations in Drug- Resistant Uropathogenic E. coli. J Pure Appl Microbiol. 2020;14(2): 1479-1485. doi: 10.22207/JPAM.14.2.45

(C) The Author(s) 2020. Open Access. This article is distributed under the terms of the Creative Commons Attribution 4.0 International License which permits unrestricted use, sharing, distribution, and reproduction in any medium, provided you give appropriate credit to the original author(s) and the source, provide a link to the Creative Commons license, and indicate if changes were made. 


\section{INTRODUCTION}

Urinary tract infection (UTI) is one of the most common causes of febrile diseases in children. In low-income countries, UTIs are ranked as the third most common bacterial infections in children ${ }^{1,2}$. E.coli is the chief uropathogen, accounting for $80 \%$ of UTIs ${ }^{3}$. The emergence of resistance among bacteria has worsened the therapeutic clinical outcome of bacterial infections ${ }^{4}$. Antimicrobial resistance in $E$. coli can be mediated by the production of extendedspectrum beta-lactamases (ESBLs) that confer resistance to all $\beta$-lactam antibiotics leading to the emergence of multidrug-resistance (MDR) $)^{5,6}$. Recently, essential oils (EOs) have been proven to serve as antimicrobials ${ }^{7}$. The synergistic effect of oil/antibiotic combinations exceeds the sum of the individual effects of the oil and antibiotic ${ }^{8}$. However, further studies are needed to elucidate mechanisms by which oils modulate bacterial drug resistance ${ }^{8}$.

Necrotoxigenic E. coli (NTEC) produces cnf1 toxin, which is considered highly lethal among bacterial toxins and is implicated in cystitis and pyelonephritis with remarkable rates ${ }^{10}$.

The present study aimed to test the antimicrobial effects of different types of EOs and investigate the in vitro efficacy of selected oil/antibiotic combinations against $E$. coli uropathogen. Furthermore, we aimed to detect the cnf 1 virulence gene by a PCR assay.

\section{EXPERIMENTAL}

\section{Collection of urine samples}

The present study included 400 urine samples collected from children suspected of having UTIs at tertiary-care paediatric hospital in the period from March 2017 to September 2017. The study conformed to the ethical guidelines of the 2013 'Helsinki Declaration' and was approved by the research committee of the paediatric hospital at Cairo University.

\section{Isolation of urinary pathogens}

Urine samples were inoculated into CLED agar plates (Oxoid, UK) and incubated at $37^{\circ} \mathrm{C}$ for $24-48 \mathrm{~h}$. Pink colonies were suspected to be $E$. coli. Isolates were further identified based on Gram staining and conventional biochemical reactions including (IMVC, TSI and urea reaction). Antimicrobial susceptibility testing of microorganisms was determined by the Kirby-Bauer disk diffusion method as per the recommendations of the Clinical and Laboratory Standards Institute. (CLSI) ${ }^{11,12}$. E. coli isolates were cultured on Muller-Hinton Agar plate with addition of Ampicillin (10 ug), amoxiciiinclavulanate (20/10ug), Ampicillin-sulbactam (10/10ug), tetracycline (30ug), trimethoprimsulfamethoxazole $(1.25 \mathrm{ug}+23.75 \mathrm{ug})$, cefazoline (30 ug), cefuroxime $(30 \mu \mathrm{g})$, ceftazidime (30ug), ceftriaxone (10ug), cefepime (30 ug), cefoxitin (30 ug)gentamicin (10ug), nalidixin acid (30ug), nitrofurantoin (300ug), and cefotaxime

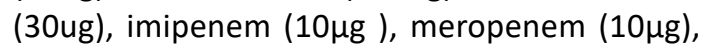
ciprofloxacin $(5 \mu \mathrm{g})$, levofloxacin $(5 \mu \mathrm{g})$. All disks were supplied from (Oxoid, UK) and were placed on the media in 20-30 mm with other disks. The boronic acid disk (Oxoid, UK) disk containing $30 \mu \mathrm{g}$ of cefoxitin and $400 \mu \mathrm{g}$ of boronic acid was added for AMPC detection also Ceftazidime- clavulanate $(30 \backslash 10 \mu \mathrm{g})$ was added for ESBL detection.

The plates were incubated for $18-24 \mathrm{~h}$ at $37^{\circ} \mathrm{C}$. E. coli (ATCC25922; American Type Culture Collection (ATCC), Manassas, VA, USA) was used as the control bacterial strain.

\section{ESBL screening}

ESBL producers were 1st identified by reduced zone diameters of ceftazidime (30ug) $\leq 22$ $\mathrm{mm}$, ceftriaxone (10 ug) $\leq 25 \mathrm{~mm}$, or Cefotaxime (30ug) $\leq 27 \mathrm{~mm}$, while ESBL confirmation was done by the double disk diffusion method where $a \geq 5$ $\mathrm{mm}$ increase in a zone diameter for Ceftazidimeclavulanate $(30 \backslash 10 \mu \mathrm{g})$ compared to ceftazidime (30ug) alone confirms ESBL production ${ }^{13}$.

\section{AMPC screening}

The organism that is resistant to cefoxitin and or demonstrated $5 \mathrm{~mm}$ or greater zone around the disk containing cefoxitin and boronic acid compared to the disk containing cefoxitin alone was considered as AmpC producer ${ }^{14}$.

\section{Detection Minimal inhibitory concentration (MIC)} for Essential oils (EOs) and antibiotics

Oils of cinnamon (Cinnamom umverum), thyme (Thymus vulgaris), clove (Syzygium aromaticum), peppermint (Mentha piperita), lavender (Lavandula angustifolia), anise (Pimpinella anisum), rosemary (Rosmarinus officinalis L.), lemongrass (Cymbopogon citratus), cumin (Cuminum cyminum) and castor bean (Ricinus communis) were obtained from the National 
Research Center (Cairo, Egypt). Each oil was tested individually against $E$. coli by the well diffusion method ${ }^{15}$ and the one with the widest inhibitory zone was selected to be tested in combination with each of 3 antibiotics (gentamycin, meropenem and cefotaxime) (Oxoid, UK). The individual MICs of EO and antibiotics against $E$. coli isolates were detected by the broth micro-dilution method in Mueller Hinton broth (Oxoid, UK) (with Tween 20 at a final concentration of $0.5 \%$ ) into a 96-well micro-plate $(2017)^{11,16,17}$. The MIC was defined as the minimal concentration of tested agent that inhibited bacterial growth ${ }^{16,17}$.

Testing the efficacy of oil/antibiotic combinations

The efficacy of the selected three oil/ antibiotic combinations was tested against 3 groups of E. coli isolates (ESBL E. coli, AMPC E. coli and non-ESBL-non-AmpC E. coli). The antimicrobial effect of the combinations was detected by the broth micro-dilution method in Mueller-Hinton broth (with Tween 20 at a final concentration of $0.5 \%$ ). Ten-fold dilutions of antibiotics and EO were prepared in a 96-well micro-plate ${ }^{9}$. The MIC values of each antibiotic and EO alone and in combination were determined, and the fractional inhibitory concentration index ( $\mathrm{FICl}$ ) was calculated according to the following equations:

FIC of antibiotic= (MIC of antibiotic in combination)/ (MIC of antibiotic alone)

$\mathrm{FIC}$ of $\mathrm{EO}=(\mathrm{MIC}$ of $\mathrm{EO}$ in combination) $/$ (MIC of EO alone)

$\mathrm{FICl}=\mathrm{FIC}$ of $\mathrm{EO}+\mathrm{FIC}$ of antibiotic

$\mathrm{FICl} \leq 0.5$, synergistic; $\mathrm{FICl}>0.5-4.0$, no interaction; $\mathrm{FICl}>4.0$, antagonism ${ }^{9}$.

The bacteriolytic effect of individual antibiotics compared to oil/antibiotic combinations was detected by measuring the optical density (O.D.) at $600 \mathrm{~nm}$.

\section{Detection of the necrotoxin gene (cnf1) by multiplex PCR}

As this study aimed at detection of (cnf1) gene and its correlation to antibiotic resistance pattern, considering the previously published study by Duzgun et al., 2019, who found that (cnf1) gene which is chromosomally encoded as the most common necrotoxin gene associated with antibiotic resistant $E$. coli in urinary tract infection ${ }^{18}$, we chose the necrotoxin gene (cnf1) to be investigated in $100 \mathrm{E}$. coli isolates by PCR assay. Bacterial DNA was extracted by the boiling method, and PCR was carried out using a set of oligonucleotide primers for $\operatorname{cnf} 1$ gene $^{19}$.

\section{RESULTS}

This study included 400 urine samples from patients clinically suspected of having UTIs, The E. coli was the chief isolate and accounted for $40.6 \%$ of the positive culture (Fig.1). ESBL and AmpC resistance patterns were found in $E$. coli with rates of $47.8 \%$ and $20.8 \%$, respectively.

Table 1 summarizes the inhibitory zones of different oils tested by well diffusion against three representative isolates of the three

Table 1. Inhibitory zone diameters (in $\mathrm{mm}$ ) of tested oils against the selected 3 groups of $E$-coli isolates

\begin{tabular}{lccc}
\hline Oil/ bacteria & $\begin{array}{c}\text { Non ESBL } \\
\text { Non-E.coli }\end{array}$ & $\begin{array}{c}\text { ESBL } \\
\text { E.coli }\end{array}$ & $\begin{array}{c}\text { AMPC } \\
\text { E.coli }\end{array}$ \\
\hline Cinnamon & 36 & 34 & 32 \\
Rosemary & 19 & 17 & 17 \\
Thyme & 27 & 22 & 21 \\
Clove & 22 & 18 & 18 \\
Peppermint & 16 & 13 & 13 \\
Lemon grasses & 17 & 16 & 16 \\
Castor & 0 & 0 & 0 \\
Lavender & 0 & 0 & 0 \\
Anise & 0 & 0 & 0 \\
Cumin & 0 & 0 & 0 \\
\hline
\end{tabular}

recovered E. coli categories (ESBL, AmpC and nonESBL-non-AmpC E. coli). The widest inhibition zone range $(3.2-3.6 \mathrm{~cm})$ was recorded for cinnamon oil. The efficacies of cinnamon oil/gentamycin, cinnamon oil /meropenem and cinnamon oil/ cefotaxime were tested against a total 15 isolates[5 isolates selected from each of the $3 \mathrm{E}$. coli groups (ESBL, AmpC and non-ESBL-AmpC)] and FICs are represented in Table 2. A synergistic effect was observed only for the cinnamon oil/gentamycin combination against $100 \%$ of the 15 tested. The calculated mean of FIC of the tested cinnamon oil/gentamycin combination showed statistically significant differences among the $3 \mathrm{E}$. coli groups (P-value $<0.001$ ). Cinnamon/gentamycin combination showed a $94 \%$ decrease in microbial growth, while gentamycin alone showed a $76 \%$ decrease (Table 3).

The cnf1 necrotoxin gene was investigated 
Hassan et al. | J Pure Appl Microbiol | 14(2):1479-1485 | June 2020 | https://doi.org/10.22207/JPAM.14.2.45

Table 2. Fractional inhibitory concentration indices ( $\mathrm{FICls}$ ) of the 3 tested oil/antibiotic combinations

\begin{tabular}{|c|c|c|c|c|c|c|c|c|c|}
\hline \multicolumn{4}{|c|}{ Isolates cinnamon/meropenem cinmer } & \multicolumn{3}{|c|}{ cinnamon/cefotaxime cincxm } & \multicolumn{3}{|c|}{ cinnamon/gentamycin cen gent } \\
\hline & $A / B$ & $A / B$ & $\mathrm{FICl}$ & $A / B$ & $A / B$ & $\mathrm{FICl}$ & $A / B$ & $A / B$ & $\mathrm{FICl}$ \\
\hline \multicolumn{10}{|c|}{ ESBL E. coli } \\
\hline 1 & $1.75 / 3.5$ & $0.0625 / 1.25$ & 0.55 & $1.75 / 3.5$ & $0.00625 / 1.25$ & 0.505 & $0.175 / 3.5$ & $0.00625 / 0.125$ & 0.1 \\
\hline 2 & $1.75 / 3.5$ & $0.0625 / 1.25$ & 0.55 & $1.75 / 3.5$ & $0.625 / 12.5$ & 0.55 & $0.175 / 3.5$ & $0.00625 / 1.25$ & 0.05 \\
\hline 3 & $1.75 / 3.5$ & $0.625 / 1.25$ & 1 & $1.75 / 3.5$ & $6.25 / 12.5$ & 1 & $0.175 / 3.5$ & $0.00625 / 1.25$ & 0.05 \\
\hline 4 & $0.175 / 0.35$ & $0.0625 / 1.25$ & 0.55 & $0.35 / 0.175$ & $0.625 / 1.25$ & 0.55 & $0.0175 / 0.35$ & $0.00625 / 0.125$ & 0.1 \\
\hline 5 & $1.75 / 3.5$ & $0.625 / 1.25$ & 1 & $1.75 / 3.5$ & $6.25 / 12.5$ & 1 & $0.175 / 3.5$ & $0.00625 / 1.25$ & 0.05 \\
\hline \multicolumn{10}{|c|}{ AmpC E. coli } \\
\hline 1 & $1.75 / 3.5$ & $0.625 / 12.5$ & 0.55 & $0.175 / 3.5$ & $0.625 / 1.25$ & 0.55 & $0.175 / 3.5$ & $0.0625 / 1.25$ & 0.1 \\
\hline 2 & $1.75 / 3.5$ & $0.625 / 12.5$ & 0.55 & $1.75 / 3.5$ & $0.625 / 12.5$ & 0.55 & $0.175 / 3.5$ & $0.0625 / 1.25$ & 0.1 \\
\hline 3 & $1.75 / 3.5$ & $6.25 / 12.5$ & 1 & $1.75 / 3.5$ & $6.25 / 12.5$ & 1 & $0.175 / 3.5$ & $0.0625 / 1.25$ & 0.1 \\
\hline 4 & $0.175 / 0.35$ & $0.625 / 12.5$ & 0.55 & $0.175 / 0.35$ & $0.0625 / 1.25$ & 0.55 & $0.0175 / 0.35$ & $0.0625 / 1.25$ & 0.1 \\
\hline 5 & $1.75 / 3.5$ & $6.25 / 12.5$ & 1 & $1.75 / 3.5$ & $6.25 / 12.5$ & 1 & $0.175 / 3.5$ & $0.0625 / 1.25$ & 0.1 \\
\hline \multicolumn{10}{|c|}{ Non ESBL-non-AmpCE. coli } \\
\hline 1 & $0.175 / 0.35$ & $0.00625 / 0.0125$ & 1 & $0.175 / 0.35$ & $0.0625 / 0.125$ & 1 & $0.00175 / 0.35$ & $0.0000625 / 0.125$ & 0.005 \\
\hline 2 & $0.175 / 3.5$ & $0.0625 / 0.125$ & 0.55 & $1.75 / 3.5$ & $0.00625 / 1.25$ & 0.505 & $0.00175 / 3.5$ & $0.0000625 / 0.125$ & 0.001 \\
\hline 3 & $1.75 / 3.5$ & $0.000625 / 0.0125$ & 0.55 & $1.75 / 3.5$ & $0.0625 / 1.25$ & 0.55 & $0.00175 / 3.5$ & $0.0000625 / 0.125$ & 0.001 \\
\hline 4 & $0.175 / 0.35$ & $0.00625 / 0.0125$ & 1 & $0.175 / 0.35$ & $0.0625 / 0.125$ & 1 & $0.00175 / 0.35$ & $0.0000625 / 0.125$ & 0.005 \\
\hline 5 & $1.75 / 3.5$ & $0.000625 / 0.0125$ & 0.55 & $1.75 / 3.5$ & $0.0625 / 1.25$ & 0.55 & $0.00175 / 3.5$ & $0.0000625 / 0.125$ & 0.001 \\
\hline
\end{tabular}

A: MIC of antibacterial agent in the most effective combination; B: MIC of antibacterial agent alone $\mathrm{FICl}$ : fractional inhibitory concentration index. $\mathrm{FICl} \leq 0.5$ synergistic; $\mathrm{FICl}>0.5-4.0$ no interaction; $\mathrm{FICl}>4.0$ antagonism (Yap et al., 2013).

by PCR in 100 out of a total of 115 recovered $E$. coli isolates, which were divided according to their susceptibility profiles into $41 \mathrm{ESBL}, 12 \mathrm{AmpC}$ and 47 non-ESBL-AmpC isolates. The cnf1 gene was detected in 40 out of $100 \mathrm{E}$. coli isolates and occurred among the $3 \mathrm{E}$. coli groups with the following frequencies: 23/41 ESBL (56.1\%), 5/12 AmpC (41.6\%), 12/47 non-ESBL-AmpC (25.5\%) (Fig.2).

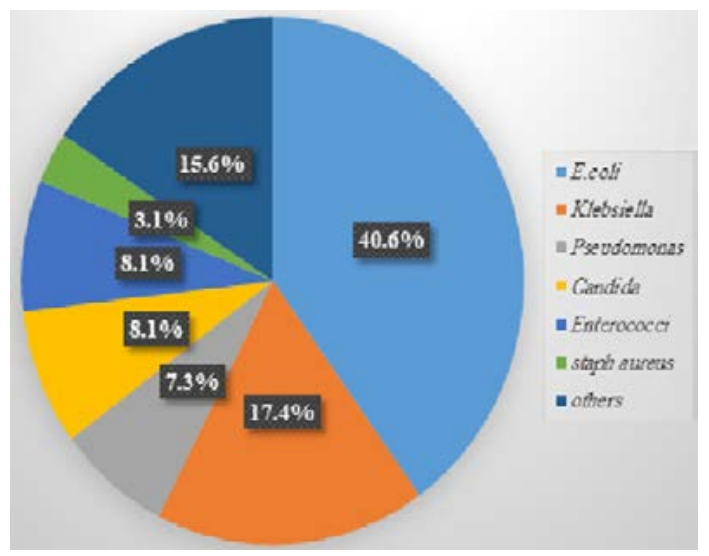

Fig. 1. Characterization of organisms isolated from urine culture.

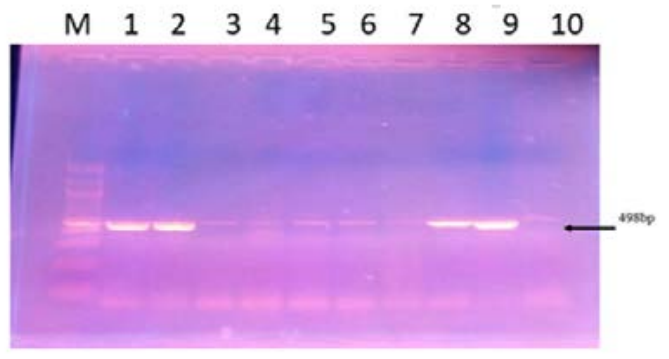

Fig. 2. Detection of cnf1 gene by PCR. Lane M: DNA ladder (100 bp); Lane 1: positive control (498 bp); Lanes (3\&4\&5\&6\&7 and 10) Negative. Lanes (2,8 and 9): Positive isolates.

\section{DISCUSSION}

UTIs are common infections in clinical practice. Approximately 150 million people are diagnosed with UTIs each year ${ }^{20}$. In the present study, $71.7 \%(287 / 400)$ of the urine samples were culture positive. This result was consistent with a study that reported positive cultures in $74.8 \%$ of urine samples; however was not complying with another study that reported a lower rate of $32.5 \%^{21,22}$. Variations in infection rates can be attributed to epidemiological variation among different geographical areas, as well as sex variation in the study population ${ }^{23}$. In the present study, E. coli accounted for $40.6 \%$ of the 
Table 3. Bacteriolytic effect of oil/antibiotic combination compared to the individual effect of the antibiotic alone

\begin{tabular}{lllll}
\hline Combinations & $\begin{array}{l}\text { Growth decrease \% } \\
\text { by antibacterial agent } \\
\text { in mix. with cinnamon }\end{array}$ & $\begin{array}{l}\text { Growth decrease \% } \\
\text { by antibacterial } \\
\text { agent alone }\end{array}$ & Chisquare & P-value \\
\hline $\begin{array}{l}\text { cinnamon/meropenem } \\
\text { on AMPC E.coli } \\
\text { cinnamon/gentamycin on }\end{array}$ & $97.8 \%$ & $89 \%$ & 0.433 & 0.510 \\
$\begin{array}{l}\text { Non ESBL-AmpCE.coli } \\
\text { cinnamon/cefotaxime on } \\
\text { non ESBL-AmpCE.coli } \\
\text { cinnamon/cefotaxime on }\end{array}$ & $94 \%$ & $76 \%$ & 1.710 & 0.191 \\
$\begin{array}{l}\text { AMPC E.coli } \\
\text { cinnamon/gentamycin } \\
\text { on ESBL E.coli }\end{array}$ & $89.2 \%$ & $85 \%$ & 1.065 & 0.302 \\
\hline
\end{tabular}

isolated uropathogens, which was consistent with many studies that reported $E$. coli as the chief uropathogen in UTIs $\mathrm{T}^{20,21,24}$. In the present study, ESBL production was demonstrated in $47.8 \%$ of the $E$. coli isolates, which was consistent with that of another study(41.9\%). ESBL production was reported at higher rates of $63.6 \%$ and $66.78 \%$ by other studies, which could be due to the criteria used to select the study populations, who had complicated UTIs ${ }^{25,26}$. According to the Infectious Diseases Society of America, ESBL-producing E. coli are among the six drug-resistant microbes for which new therapies need to be developed ${ }^{27}$.

Many studies have been published on the antimicrobial properties of plant extracts against different microbes ${ }^{28-30}$ especially cinnamon oil, as a safe antimicrobial alternative. Cinnamon oil at least partially gets metabolized into cinnamic acid in stomach and small intestine and almost completely gets metabolized into cinnamic acid in liver before it is absorbed into blood ${ }^{31}$. As reported by several studies, cinnamon oil has a powerful antimicrobial effect due to deformation of the microbial cytoplasmic membrane ${ }^{28-30}$. In the present study, cinnamon oil showed the strongest antibacterial effect, with a significant difference (P-value $<0.001$ ) among the three $E$. coli groups (ESBL E. coli, AmpC E. coli and non-ESBL-AmpC E. coli), which agreed with several previous reports 22,28,32,33, however opposed by a study that showed no synergy ${ }^{34}$. The present study had the advantage of testing oil/antibiotic combinations against drug- resistant $E$ - coli isolates from patients, as most of published reports tested ATCC drug- susceptible strains ${ }^{15}$.

The cnf1 virulence gene was detected in $40 \%$ of isolates. Several studies reported variable prevalence rates of $61 \%, 22.9 \%$ and $37 \%$, that could be attributed to different study population ${ }^{35-37,39}$. Previous studies showed that the NTEC isolates had variable degrees of resistance towards antimicrobial agents ${ }^{19}$. Moreover, it was assumed that $E$-coli serotypes involved in $c n f 1$ production differ from those of ESBL production ${ }^{19,38}$.

\section{CONCLUSIONS}

ESBL production and cnf1 gene were detected among $E$. coli urinary isolates with considerable rates. Synergy was only observed with Cinnamon oil/gentamycin combination. Further clinical researches shall be conducted to introduce promising oil/antibiotic combinations into clinical field.

\section{ACKNOWLEDGMENTS}

We would like to thank Abu ElRich AlMonira 3ry care pediatric hospital laboratory staff (faculty of medicine, Cairo university)for providing assistance on methods through out this research.

\section{AUTHORS' CONTRIBUTION}

All authors listed have made a substantial, direct and intellectual contribution to the work, and approved it for publication. 


\section{DATA AVAILABILITY}

All datasets generated or analyzed during this study are included in the Supplementary Files.

\section{CONFLICT OF INTEREST}

The authors declare that there is no conflict of interest.

\section{FUNDING}

None

\section{ETHICS STATEMENT}

This article does not contain any studies involving animals or human participants performed by any of the authors

\section{REFERENCES}

1. Uwaezuoke SN, The prevalence of urinary tract infection in children with severe acute malnutrition: a narrative review. Pediatric Health Med Ther. 2016;7:121-127. https://doi.org/10.2147/PHMT. S107421

2. Bagga A, Tripathi $P$, Jatana $V$, et al. Bacteruria and urinary tract infections in malnourished children. Pediatr Nephrol. 2003;18(4):366-370. https://doi. org/10.1007/s00467-003-1118-0

3. Wurpel DJ, Moriel DG, Totsika M, Easton DM, Schembri MA. Comparative analysis of the uropathogenic Escherichia coli surface proteome by tandem massspectrometry of artificially induced outer membrane vesicles. J Proteomics. 2015;115:93-106. https://doi. org/10.1016/j.jprot.2014.12.005

4. Bhardwaj M, Singh BR, Sinha DK. Vet al. Potential of Herbal Drug and Antibiotic Combination Therapy: A New Approach to Treat Multidrug Resistant Bacteria. Pharm Anal Acta. 2016;7:11. https://doi. org/10.4172/2153-2435.1000523

5. Sabir S, Anjum AA, ljaz T. et al. Isolation and antibiotic susceptibility of $E$. coli from urinary tract infections in a tertiary care hospital. Pak J Med Sci. 2014;30(2):389392. https://doi.org/10.12669/pjms.302.4289

6. Mwanyika GO, Subbiah M, Buza J, Rugumisa BT, Call DR. A systematic review of antibiotic-resistant Escherichia coli and Salmonella data obtained from Tanzanian healthcare settings (2004-2014). Afr J Microbiol. 2017;11(2):45-54. https://doi.org/10.5897/ AJMR2016.8282

7. Yap PSX, Lim SHE, Hu CP, Yiap BC. Combination of essential oils and antibiotics reduce antibiotic resistance in plasmid-conferred multidrug resistant bacteria. Phytomedicine. 2017;20:710-713. https:// doi.org/10.1016/j.phymed.2013.02.013

8. Bassole IH, Julian HR. Essential oils in combination and their antimicrobial properties. Molecules. 2012;17:3989-4006. https://doi.org/10.3390/ molecules17043989

9. Yap PS, Yiap BC, Ping HC, Lim SH. Essential oils, a new horizon in combating bacterial antibiotic resistance.
Open Microbiol J. 2014;7(8):6-14. https://doi. org/10.2174/1874285801408010006

10. Cespedes S, Saitz W, Del Canto F, et al. Genetic diversity and Virulence Determinants of Escherichia coli Strains Isolated from Patients with Crohn's Disease in Spain and Chile. Front Microbiol. 2017;8:639. https://doi. org/10.3389/fmicb.2017.00639

11. Performance Standards for antimicrobial susceptibility testing, $27^{\text {th }}$ Informational Supplement, CLSI document M100-S27, Clinical and Laboratory Standard Institute (CLSI), 2017. www.pelagiaresearchlibrary.com

12. Zahera $M$, Rastogi $\mathrm{CH}$, Singh $\mathrm{P}$, IramS, Khalid $\mathrm{SH}$, Kushwaha A. Isolation, Identification and Characterization of Escherichia coli from Urine Samples and their Antibiotic Sensitivity Pattern. Eur J Exp Biol. 2011;1(2):118-124. www.pelagiaresearchlibrary.com

13. Lan N, Hien N, Phuong T, et al. Antimicrob Resist Infect Control. 2017;6:105. https://doi.org/10.1186/s13756017-0265-1

14. Pitout JDD, Laupland KB. Review extended-spectrum $\beta$-lactamase-producing Enterobacteriaceae: an emerging public-health concern. Lancet Infect Dis. 2008;8(3):159-66. https://doi.org/10.1016/S14733099(08)70041-0

15. Mith H, Dure R, Delcenserie V, Zhiri A, Daube G, Clinquart A. Antimicrobial activities of commercial essential oils and their components against food-borne pathogens and food spoilage bacteria. Food Sci Nutr. 2014;2(4):403- 416. https://doi.org/10.1002/fsn3.116

16. Mohamed SH, Mohamed MSM, Khalil MS, Azmy M, Mabrouk MI. Combination of essential oil and ciprofloxacin to inhibit/ eradicate biofilms in multidrug-resistant Klebsiella pneumonia. J Appl Microbiol. 2018;125(1):84-95. https://doi. org/10.1111/jam.13755

17. Abdel-Moaty MM, El-Hendawy HH, Mohamed WS, Abdel-All SM. A potential role of cinnamon bark essential oil and its major component in enhancing antibiotics effect against clinical isolates of extendedspectrum beta-lactamase producing Escherichia coli. Der. Pharmacia. Lettre. 2016;8(7):138-147.

18. Duzgun A, Okumus F, Saral A, Cicek C, Cinemre $S$. Determination of antibiotic resistance genes and virulence factors in Escherichia coli isolated from Turkish patients with urinary tract infection. Journal of the Brazilian Society of Tropical Medicine. 2019;52:e20180499. https://doi.org/10.1590/00378682-0499-2018

19. Rahman H, Deka M. Detection \& characterization of necrotoxin producing Escherichia coli (NTEC) from patients with urinary tract infection (UTI). Indian J Med Res. 2014;139(4):632-637.400. [PubMed: 24927352]

20. Qiao LD, Chen S, Yang Y, et al. Characteristics of urinary tract infection pathogens and their invitro susceptibility to antimicrobial agents in China: data from a multicenter study. BMJ Open. 2013;3(12):e004152. https://doi.org/10.1136/bmjopen-2013-004152

21. AlYousef SL, Farrag E, Moussa HS, Bayoumi FS, Ali AM. Clinical and Laboratory Profile of Urinary Tract Infections Associated with Extended Spectrum $\beta$ Lactamase Producing Escherichia coli and Klebsiella pneumonia. Ann Clin Lab Sci. 2016;46(4):393. 
22. Anandharaj B, Saju Varghese S. Efficacy of Spice Extracts against UTI Isolates. Int $J$ Curr Microbiol A Sci. 2015;4(6):494-500.

23. Shaheen HM, Farahat TM, Hammad NAE. Prevalence of urinary tract infection among pregnant women and possible risk factors. Menoufia Med J. 2016;29:10551059.

24. Okonko IO, ljandipe L, llusanya A, et al. Detection of urinary tract infection (UTI) among pregnant women in Oluyoro Catholic Hospital, Ibadan, South-Western Nigeria. Mal J Microbiol. 2010;6(1):16-24. https://doi. org/10.21161/mjm.14708

25. Ranjan N. Complicated urinary tract infection caused by extended spectrum $\beta$-lactamase-producing Escherichia coli. Urol Ann. 2014;6(2):112-113. https:// doi.org/10.4103/0974-7796.130536

26. Ranjan KP, Picozzi SCM. Castello S. et al. Extendedspectrum beta-lactamase-positive Escherichia coli causing complicated upper urinary tract infection: Urologist should act in time. Urol Ann. 2014;6(2):107112. https://doi.org/10.4103/0974-7796.130536

27. Pitout JD, Laupland KB. Extended-spectrum betalactamase-producing Enterobacteriacae: an emerging public-health concern. Lancet Infect Dis. 2008;8(3):159166. https://doi.org/10.1016/S1473-3099(08)70041-0

28. Oulkheir S, Aghrouch M, El Mourabit F, et al., Antibacterial Activity of Essential Oils Extracts from Cinnamon, Thyme, Clove and Geranium Against a Gram Negative and Gram Positive Pathogenic Bacteria. J Dis Med Plants. 2017;3(2-1):1-5.

29. Chouhan S, Sharma K, Guleria S. Antimicrobial Activity of Some Essential Oils-Present Status and Future Perspectives. Medicines. 2017;4:58. https://doi. org/10.3390/medicines4030058

30. Valizadeh A, Shirzad M, Esmaeili F, Amani A. Increased antibacterial activity of Cinnamon Oil Microemulsionin Comparison with Cinnamon Oil Bulk and Nanoemulsion. Nanomed Res J. 2018;3(1):37-43. doi:10.22034/NMRJ.2018.01.006

31. El-Sayed M, Abd El-Raouf O, Fawzy H, Manie M.
Cinnamic Acid and Cinnamaldehyde Ameliorate Cisplatin-Induced Splenotoxicity in Rats. I Biochem Mol Toxicol. 2015. https://doi.org/10.1002/jbt.21715

32. Santurio DF, De Jesus FPK, Zanette RA, Schlemmer KB, Fraton A, Fries L. Antimicrobial Activity of the Essential Oil of Thyme and of Thymol against Escherichia coli. Acta Sci Vet. 2014;42(1):1-4.

33. Sousa EO, Silva NF, Rodrigues FF, Campos AR, Lima SG, Costa JG. Chemical composition and resistancemodifying effect of the essential oil of Lantana camara. Linn Pharmacogn Mag. 2010;6:79-82. https://doi. org/10.4103/0973-1296.62890

34. Padalia H, Rathod T, Moteriya P, Chanda S. Antimicrobial Efficacy of Cinnamonumverum Essential Oil Alone and in Combination with Antibiotics and Other Essential Oils. Int J Curr Microbiol A Sci. 2017;6(11): 3377-3395.

35. Marrs CF, Zhang L, Foxman B. Escherichia coli mediated urinary tract infections: are there distinct uropathogen E.coli (UPEC) pathotypes? FEMS Microbiol Lett. 2005;252(2):183-190.

36. Farshad S, Emamghorashi F. The prevalence of virulence genes of $E$. coli strains isolated from children with urinary tract infection. Saudi J Kidney Dis Transpl. 2009;20(4):613-617.

37. Aslam M, Service C. Antimicrobial resistance and genetic profiling of Escherichia coli from a commercial beef packing plant. J Food Prot. 2006;69(7):1508-13. https://doi.org/10.4315/0362-028X-69.7.1508

38. Sharma S, Kaur N, Malhotra S, Madan P, Ahmad W, Hans C. Serotyping and Antimicrobial Susceptibility Pattern of Escherichia coli Isolates from Urinary Tract Infections in Pediatric Population in a Tertiary Care Hospital. J Pathog. 2016;2016:2548517 https://doi. org/10.1155/2016/2548517

39. Lopez-Banda D, Carrillo-Casa EM, Leyva-Leyva M, et al., Identification of Virulence Factors Genes in Escherichia coli Isolates from Women with Urinary Tract Infection in Mexico. BioMed Res Int. 2014. https://doi.org/10.1155/2014/959206 